\title{
Index of Orthodontic Treatment Need of Patients undergoing Orthodontic Treatment at BPKIHS, Dharan
}

\author{
Dr Rajesh Gyawali,, Dr Prabhat Ranjan Pokharel,, Dr Jamal Giri, ${ }^{3}$ Dr Gunjan Kumar Shrestha,, \\ Dr Bhushan Bhattarai \\ ${ }^{3}$ Assistant Professor, ${ }^{2}$ Associate Professor, Dept of Orthodontics, \\ B.P. Koirala Institute of Health Sciences, Dharan, Nepal \\ ${ }^{4}$ Lecturer, Dept of Orthodontics, MB Kedia Dental College, Birgunj, Nepal \\ sLecturer, Dept of Orthodontics, Nobel Medical College, Biratnagar, Nepal
}

Correspondence: Dr Rajesh Gyawali; Email: gyawalirajesh@gmail.com

\section{ABSTRACT}

Introduction: Measurement of the severity of malocclusion is assessed with various indices among which Index of Orthodontic Treatment Need (IOTN) is widely used for clinical and epidemiological purpose.

Objective: To find out the treatment need of patients who are undergoing orthodontic treatment.

Materials \& Method: 207 patients (71 male, 136 female) fulfilling the inclusion criteria were assessed for the dental health component (DHC) and aesthetic component (AC) of the Index of Orthodontic Treatment Need (IOTN) by a single investigator. DHC was assessed with study models, whereas AC with intraoral frontal photograph.

Result: Examination of DHC showed that 1 patient (0.5\%) had no need; 20 patients (9.7\%) had mild/little need; 50 patients (24.2\%) had moderate/borderline need; 97 (46.9\%) had severe need; 39 patients (18.8\%) had extreme treatment need. Similarly, 7 patients (3.4\%) had AC 1; 18 patients (8.7\%) had AC 2; 13 patients (6.3\%) had AC 3; 32 patients (15.5\%) had AC 4; 34 patients (16.4\%) had AC 5; 25 patients (12.1\%) had AC 6; 18 patients (8.7\%) had AC $7 ; 35$ patients (16.9\%) had AC $8 ; 15$ patients (7.2\%) had AC 9; 10 patients (4.8\%) had AC 10.

Conclusion: Among the patients who were undergoing orthodontic treatment, majority were in severe/extreme treatment need, however few with no treatment need were also found.

Keywords: Index of Orthodontic Treatment Need, malocclusion, orthodontic treatment, severity

\section{INTRODUCTION}

Malocclusion whether involving dental and/or skeletal component may lead to various problems like poor oral function, poor facial appearance, temporomandibular dysfunction, problems with mastication, swallowing, speech; susceptibility to trauma, periodontal disease or decay; and psychological problems. It is the most common dental problem with high prevalence.'

The need for orthodontic treatment is usually assessed with the help of various indices. Some of them are handicapping Labio-labial Deviation Index, ${ }^{2}$ Swedish Medical Board Index $(\mathrm{SMBI}),{ }^{3}$ Dental Aesthetic Index (DAI), ${ }^{4}$ Index of Orthodontic Treatment Need (IOTN) ${ }^{5}$ and Index of Complexity, Outcome and Need (ICON). ${ }^{6}$ These indices help in identifying the orthodontic treatment need and plan orthodontic services. IOTN; developed by Peter Brook and William Shaw was initially called as Index of Orthodontic Treatment Priority, is now widely used for clinical and epidemiological purposes.?
Several studies have been conducted to measure the prevalence and severity of malocclusion in different populations,, 814 but no study has been found to assess the severity of malocclusion in patients undergoing orthodontic treatment. This study aims to find the treatment need of patients who are undergoing orthodontic treatment so as to assess the severity of malocclusion.

\section{MATERIALS AND METHOD}

The study was started after ethical clearance and approval from the Research Committee of BP Koirala Institute of Health Sciences. The sample consisted of 207 patients who were undergoing orthodontic treatment in the Department of Orthodontics, College of Dentistry, BPKIHS, Dharan. The study models and photographs of the patients from the records of the department were used in assessment of IOTN. Records of patients with poor quality photographs and broken/missing study models were excluded. 
Table 1: Distribution of DHC among male and female

\begin{tabular}{|l|c|c|c|c|c|c|}
\hline & \multicolumn{6}{|c|}{ IOTN - Dental Health Component } \\
\cline { 2 - 7 } & $\begin{array}{c}\text { Grade 1 } \\
\text { No need }\end{array}$ & $\begin{array}{c}\text { Grade 2 } \\
\text { Little need }\end{array}$ & $\begin{array}{c}\text { Grade 3 } \\
\text { Moderate need }\end{array}$ & $\begin{array}{c}\text { Grade 4 } \\
\text { Severe need }\end{array}$ & $\begin{array}{c}\text { Grade 5 } \\
\text { Extreme need }\end{array}$ & Total \\
\hline Female & 1 & 12 & 36 & 60 & 27 & 13 \\
\hline Male & 0 & 8 & 14 & 37 & 39 & 207 \\
\hline Total & 1 & 20 & 50 & 97 & 71 \\
\hline
\end{tabular}

Table 2: Distribution of $A C$ among male and female

\begin{tabular}{|c|c|c|c|c|c|c|c|c|c|c|c|}
\hline & \multicolumn{10}{|c|}{ IOTN - Dental Health Component } & \multirow[b]{2}{*}{ Total } \\
\hline & $\begin{array}{c}\text { Grade } \\
1\end{array}$ & $\begin{array}{c}\text { Grade } \\
2\end{array}$ & $\begin{array}{c}\text { Grade } \\
3\end{array}$ & $\begin{array}{c}\text { Grade } \\
4\end{array}$ & $\begin{array}{c}\text { Grade } \\
5\end{array}$ & $\begin{array}{c}\text { Grade } \\
\quad 6\end{array}$ & $\begin{array}{c}\text { Grade } \\
7\end{array}$ & $\begin{array}{c}\text { Grade } \\
8\end{array}$ & $\begin{array}{c}\text { Grade } \\
9\end{array}$ & $\begin{array}{c}\text { Grade } \\
10\end{array}$ & \\
\hline Female & 5 & 15 & 7 & 20 & 24 & 19 & 11 & 20 & 7 & 8 & 136 \\
\hline Male & 2 & 3 & 6 & 12 & 10 & 6 & 7 & 15 & 8 & 2 & 71 \\
\hline Total & 7 & 18 & 13 & 32 & 34 & 25 & 18 & 35 & 15 & 10 & 207 \\
\hline
\end{tabular}

Table 3: Correlation of IOTN with gender

\begin{tabular}{|l|c|c|}
\hline & Pearson Correlation & Sig 2-tailed \\
\hline DHC and AC in male & 0.475 & $0.000^{*}$ \\
\hline DHC and AC in female & 0.468 & $0.000^{*}$ \\
\hline DHC and AC in total & 0.469 & $0.000^{*}$ \\
\hline
\end{tabular}

*Significant at $p<0.05$

Figure 1: Distribution of Dental Health Component

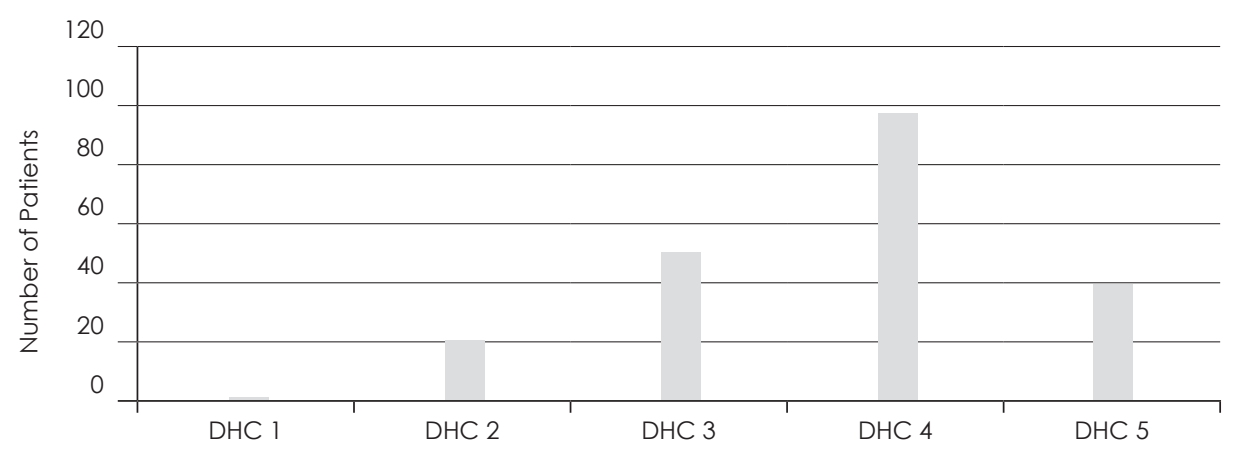

Figure 2: Distribution of Aesthetic Component

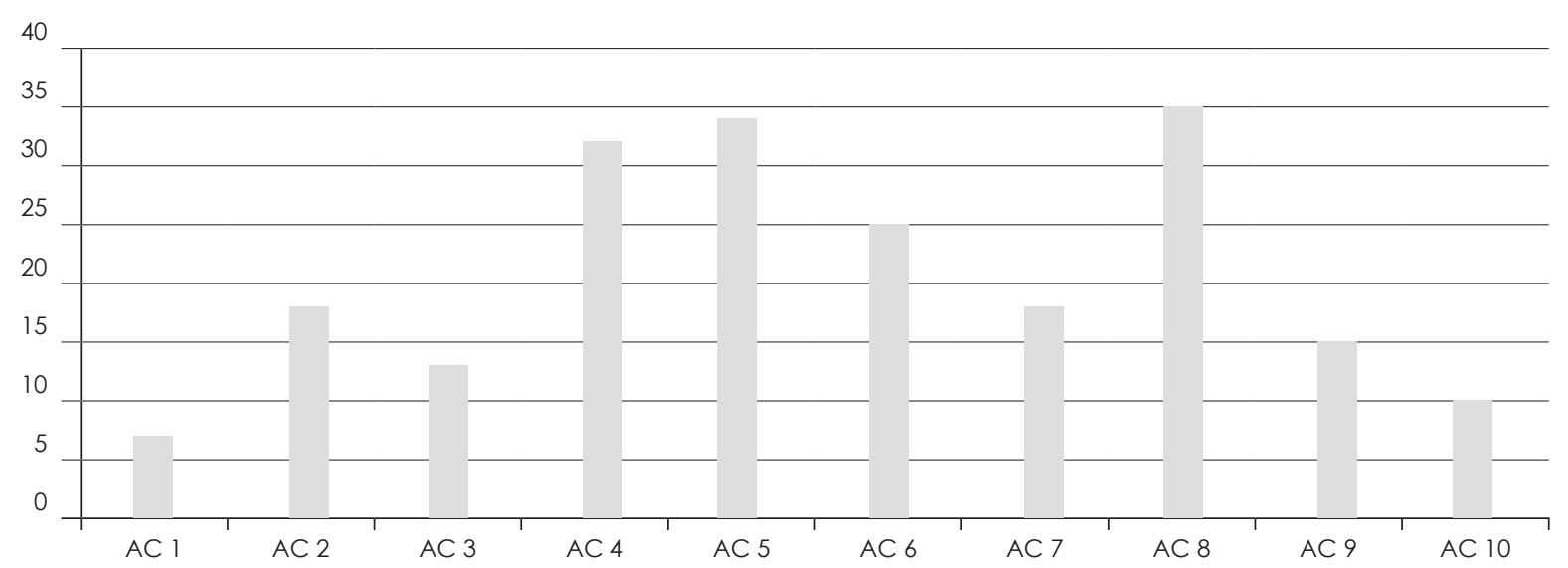


Table 4: Comparison of IOTN - DHC data of Eastern Nepal

\begin{tabular}{|l|c|c|c|c|c|}
\hline \multicolumn{1}{|c|}{ Study } & Grade I & Grade II & Grade III & Grade IV & Grade V \\
\hline Prevalence in population $^{21}$ & $15.02 \%$ & $14.7 \%$ & $24.07 \%$ & $24.67 \%$ & $21.59 \%$ \\
\hline Presented to the hospital ${ }^{11}$ & $1 \%$ & $8.9 \%$ & $28.1 \%$ & $47 \%$ & $15 \%$ \\
\hline Undergoing treatment (present study) & $0.5 \%$ & $9.7 \%$ & $24.2 \%$ & $46.9 \%$ & $18.8 \%$ \\
\hline
\end{tabular}

The two components of IOTN viz: Dental Health Component (DHC) and Aesthetic component (AC) were both evaluated by Principal Investigator only. DHC was assessed with the study models and classified into five categories according to the severity; i.e. Grade 1- no treatment need; Grade 2mild/little treatment need; Grade 3- moderate/borderline treatment need; Grade 4- severe treatment need; Grade 5- extreme treatment need. AC was assessed with the intraoral frontal photographby comparing with the 10-grade reference photographs of different dental attractiveness. Intra-examiner reliability was assessed by calculating kappa statistics in which records of 50 patients were reassessed after 15 days. The Kappa value of intra-examiner reliability was found to be 0.70 for $\mathrm{AC}$ and 0.76 for DHC showing substantial agreement. All the data were analyzed with SPSS Version 20.

\section{RESULT}

Out of the records of 207 selected patients; two third were female (71 male and 136 female). On examining the DHC, it was found that 1 patient $(0.5 \%)$ had no need; 20 patients (9.7\%) had mild/little need, 50 patients (24.2\%) had moderate/ borderline need, 97 (46.9\%) had severe need, and 39 patients (18.8\%) had extreme treatment need (Table 1 and Figure 1).

Similarly the grading of $\mathrm{AC}$ were: 7 patients (3.4\%) $\mathrm{AC}-1,18$ patients (8.7\%) AC-2, 13 patients (6.3\%) AC-3, 32 patients (15.5\%) AC-4, 34 patients (16.4\%) AC-5, 25 patients (12.1\%) AC-6, 18 patients (8.7\%) AC-7, 35 patients (16.9\%) AC-8, 15 patients (7.2\%) AC-9, and 10 patients (4.8\%) AC-10 (Table 2 and Figure 2).

Relationship between $\mathrm{DHC}$ and $\mathrm{AC}$ grades with gender showed increased number of females in each grade. Also there was a significant positive correlation between $\mathrm{DHC}$ and AC values (Table 3 ).

\section{DISCUSSION}

The prevalence of malocclusion varies according to the population. ${ }^{15-19}$ The prevalence of malocclusion in Nepal varies from $73 \%$ to $90.4 \%{ }^{1}{ }^{120,21}$ Planning orthodontic treatment in the population requires data regarding malocclusion and its severity at the community level. Several studies were done to assess the severity of malocclusion in the population. ${ }^{3,22-24}$ These data show the picture present in the community, but studies revealing similar data among orthodontic clinics are scarce. ${ }^{14,31}$
This study was done to assess the severity of malocclusion among the orthodontic patients in a tertiary referral center of eastern Nepal. It should be noted that, those who possess malocclusion may not present to the orthodontic clinic and among those who presented, may not go ahead with the treatment. Thus this study reports the status of those who are undergoing orthodontic treatment.

A survey among 2050 people of United Kingdom showed that $45 \%$ of adults are unhappy with their teeth, $20 \%$ would like to have some form of orthodontic treatment done. ${ }^{25}$ However, very less people actually go ahead for orthodontic treatment. Many studies found both patients and parents to be satisfied with the orthodontic treatment. ${ }^{26,27}$ Because of poor socioeconomic condition; many of those who actually need orthodontic treatment could not afford the treatment. ${ }^{28}$

Although orthodontist considers esthetics, function and oral health in evaluating the need for orthodontic treatment, most patients are bothered about esthetics only and it is the prime reason for seeking the treatment. ${ }^{29}$ Because of the subjective nature of esthetic assessment, some patients may feel a 'great need' for treatment even though he/she falls under 'no need' category according an orthodontist. ${ }^{30}$ This might be the reason for few patients with 'no treatment need' being treated in the orthodontic clinic.

When comparing the data of eastern Nepal regarding the severity of malocclusion, there is a great difference in grades among the people in community and those who present in orthodontic clinic. It is obvious that those who have less need of treatment are unlikely to present themselves to the orthodontist. The percentage of patients who presented to the hospital and who are undergoing orthodontic treatment is more or less the same at each grade of DHC (Table 4).

The number of orthodontic patients with greater needs of orthodontic treatment is very high. With a very few numbers of orthodontists in more than 26 million population of the country; providing the orthodontic care is challenging. ${ }^{32,33}$ The high cost of orthodontic treatment makes it difficult to the low socioeconomic group which is beyond the reach of the common people. Further, the accumulation of orthodontists in urban areas has made the difficulty in access for rural people to orthodontic services. 


\section{CONCLUSION}

Among the eastern Nepalese patients who were undergoing orthodontic treatment, the majority is in 'severe treatment need'; contrarily very few do not need orthodontic treatment.
Every effort should be made by the concerned authorities so that more needy people can avail the orthodontic service.

\section{REFERENCES}

1. Shrestha BK, Yadav R, Gyawali R, Gupta S. Prevalence of malocclusion among medical students in Institute of Medicine, Nepal: A Preliminary report. Orthod J Nep. 2013; 1(1):24-7.

2. Draker HL. Handicapping labio-lingual deviations: A proposed index for public health purposes. Am J Orthod. 1960; 46(4):295-305.

3. Linder-Aronson S. Orthodontics in the Swedish public dental health service. Trans Euro Orthod Soc. 1974:233.

4. Cons NC, Jenny J, Kohout FJ. DAl--the Dental Aesthetic Index: College of Dentistry, University of lowa, lowa City; 1986.

5. Brook PH, Shaw WC. The development of an index of orthodontic treatment priority. Euro J Orthod. 1989; 11 (3):309-20.

6. Daniels C, Richmond S. The development of the index of complexity, outcome and need (ICON). J Orthod. $2000 ; 27(2): 149-62$.

7. Al Yami EA, Kuijpers-Jagtman AM, Van't Hof MA. Assessment of dental and facial aesthetics in adolescents. Euro J Orthod. 1998; 20(4):399-405.

8. Behbehani F, Årtun J, Al-Jame B, Kerosuo H. Prevalence and severity of malocclusion in adolescent Kuwaitis. Med Principles and Practice. 2005;14(6):390-5.

9. Hill P. The prevalence and severity of malocclusion and the need for orthodontic treatment in 9-, 12-, and 15-year-old Glasgow schoolchildren. Br J Orthod. 1992; 19(2):87-96.

10. Steigman S, Kawar M, Zilberman Y. Prevalence and severity of malocclusion in Israeli Arab urban children 13 to 15 years of age. Am $J$ Orthodontics. 1983; 84(4):337-43.

11. Baca-Garcia A, Bravo M, Baca P, Baca A, Junco P. Malocclusions and orthodontic treatment needs in a group of Spanish adolescents using the Dental Aesthetic Index. Int Dent J. 2004; 54(3):138-42.

12. Mills LF. Epidemiologic studies of occlusion IV. The prevalence of malocclusion in a population of 1,455 school children. J Dent Res. 1966 ; 45(2):332-6.

13. Alhaija ESA, Al-Nimri KS, Al-Khateeb SN. Orthodontic treatment need and demand in 12-14-year-old north Jordanian school children. Euro J Orthod. 2004; 26(3):261-3.

14. Shrestha S, Shrestha RM. Index of Orthodontic Treatment Need in Referred Nepalese Population. Orthod J Nep. $2013 ; 2$ (1):9-15.

15. Helm S. Malocclusion in Danish children with adolescent dentition: An epidemiologic study. Am J Orthod. 1968; 54(5):352-66.

16. Massler M, Frankel JM. Prevalence of malocclusion in children aged 14 to 18 years. Am J Orthod. 1951; 37(10):751-68.

17. Silva RG, Kang DS. Prevalence of malocclusion among Latino adolescents. Am J Orthod Dentofac Orthop. 2001; 119(3):313-5.

18. Thilander B, Pena L, Infante C, Parada SS, de Mayorga C. Prevalence of malocclusion and orthodontic treatment need in children and adolescents in Bogota, Colombia. An epidemiological study related to different stages of dental development. Euro J Orthod. 2001 ; 23(2):153-68.

19. Tausche E, Luck O, Harzer W. Prevalence of malocclusions in the early mixed dentition and orthodontic treatment need. Euro J Orthod. 2004; $26(3): 237-44$

20. Shrestha BK, Yadav R, Basel P. Prevalence of malocclusion among high school students in Kathmandu valley. Orthod J Nep. 2012;2:1.

21. Singh VP, Sharma A. Epidemiology of Malocclusion and Assessment of Orthodontic Treatment Need for Nepalese Children. International Scholarly Research Notices. 2014; 2014.

22. Markazi Moghadam M, Moghimbeigi A, Jafari F. Evaluation of Orthodontic Treatment Needs in a population of Iranian Schoolchildren using the IOTN in 2010

23. Hedayati Z, Fattahi H, Jahromi S. The use of Index of Orthodontic Treatment Need in an Iranian population. J Ind Soc Pedod Prev Dent. 2007; 25(1):10.

24. Manzanera D, Almerich-Silla JM, Gandía JL. Orthodontic treatment need in Spanish schoolchildren: An epidemiological study using the Index of Orthodontic Treatment Need. Euro J Orthod. 2009; 31 (2):180-3.

25. BOS. Picture perfect for NOW launch. Dental Tribune United Kingdom Ed. March 29 - April 4, 2010.

26. Oliver R, Knapman Y. Attitudes to orthodontic treatment. Br J Orthod. 1985; 12(4):179-88.

27. Keles F, Bos A. Satisfaction with orthodontic treatment. Angle Orthod. 2012; 83(3):507-11.

28. Tickle M, Kay EJ, Bearn D. Socio-economic status and orthodontic treatment need. Comm Dent Oral Epidemio. 1999; $27(6): 413-8$.

29. Gosney M. An investigation into some of the factors influencing the desire for orthodontic treatment. Br J Orthod. 1986; 13(2):87-94.

30. Shaw W. Factors influencing the desire for orthodontic treatment. Euro J Orthod. 1981; 3(3):151-62.

31. Sharma JN. Epidemiology of malocclusions and assessment of orthodontic treatment need for the population of eastern Nepal. World J Orthod. 2008; 10(4):311-6.

32. Shrestha RM. Orthodontic Scenario of Nepal. Orthod J Nep. 2013; 3(1):5-6.

33. Nepal Demographic Health Survey. Census. Ramshah Path, Kathmandu: Central Bureau of Statistics; 2011. 